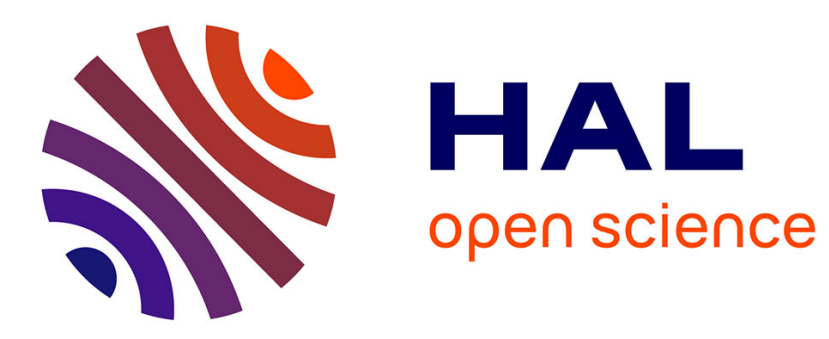

\title{
Structure-function insights into elusive Mycobacterium tuberculosis protein Rv1916
}

Monika Antil, Jyoti Sharma, Yoan Brissonnet, Monika Choudhary, Sébastien Gouin, Vibha Gupta

\section{- To cite this version:}

Monika Antil, Jyoti Sharma, Yoan Brissonnet, Monika Choudhary, Sébastien Gouin, et al.. Structurefunction insights into elusive Mycobacterium tuberculosis protein Rv1916. International Journal of Biological Macromolecules, 2019, 141, pp.927-936. 10.1016/j.ijbiomac.2019.09.038 . hal-03003095

\section{HAL Id: hal-03003095 \\ https://hal.science/hal-03003095}

Submitted on 27 Nov 2020

HAL is a multi-disciplinary open access archive for the deposit and dissemination of scientific research documents, whether they are published or not. The documents may come from teaching and research institutions in France or abroad, or from public or private research centers.
L'archive ouverte pluridisciplinaire HAL, est destinée au dépôt et à la diffusion de documents scientifiques de niveau recherche, publiés ou non, émanant des établissements d'enseignement et de recherche français ou étrangers, des laboratoires publics ou privés. 


\section{Structure Function insights into elusive Mycobacterium tuberculosis protein Rv1916}

Monika Antil $^{\mathrm{a}}$, Jyoti Sharma ${ }^{\mathrm{b}, \mathrm{c}}$, Yoan Brissonnet ${ }^{\mathrm{d}}$, Monika Choudhary ${ }^{\mathrm{e}}$, Sébastien Gouin $^{\text {d }}$ and Vibha Gupta*

a Department of Biotechnology, Jaypee Institute of Information Technology, Noida - 201309, India

${ }^{\mathrm{b}}$ Institute of Bioinformatics, International Technology Park, Bangalore, 560066 India

${ }^{\mathrm{c}}$ Manipal Academy of Higher Education (MAHE), Manipal 576104, Karnataka, India

${ }^{\mathrm{d} C E I S A M, ~ C h i m i e ~ E t ~ I n t e r d i s c i p l i n a r i t e ́, ~ S y n t h e ̀ s e, ~ A n a l y s e, ~ M o d e ́ l i s a t i o n, ~ U M R ~ C N R S ~}$ 6230, UFR des Sciences et des Techniques, Université de Nantes, 2 rue de la Houssinière, BP 92208, 44322, Nantes Cedex 3, France.

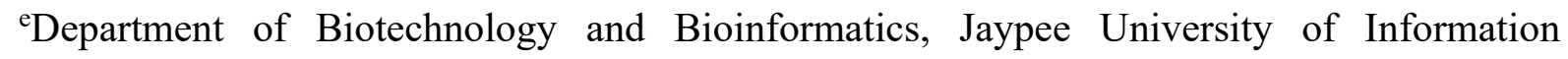
Technology, Waknaghat - 173234, India

\section{Author contributions}

MA prepared the recombinant constructs, purified them and performed all the experiments; JS performed the model building and phylogenetic analysis; YB synthesized 2methylisocitrate and SG supervised related experiments; MC carried out isoelectric focusing experiments, MA and VG discussed the results and wrote the manuscript. VG designed and supervised the study.

*Corresponding author:

Dr. Vibha Gupta

Department of Biotechnology

Jaypee Institute of Information Technology

A-10, Sector-62, Noida- 201309

Uttar Pradesh, India

Email: vibha.gupta@jiit.ac.in

Co-authors: $\quad$ Monika Antil

Email: monikaanti160@gmail.com

Jyoti Sharma

Email: jyotibioinfo@gmail.com

Sébastien Gouin

Email: Sebastien.Gouin@univ-nantes.fr

Yoan Brissonnet

Email: yoan.brissonnet@univ-nantes.fr

Monika Choudhary

Email: monikachoudhary485@gmail.com 


\section{ABSTRACT}

Tuberculosis (TB) is one of the leading causes of death worldwide. This is due to the ability of causative organism Mycobacterium tuberculosis (Mtb), to persist inside the host cells, leading to the long duration of TB therapy and therefore, development of drug resistant strains of $M t b$. Novel drug targets against persistent $M t b$ is an immediate need for overcoming this global menace. Enzymes of glyoxylate pathway are essential for persistent $M t b$ and not present in humans, hence propitious targets for drug development. Isocitrate lyase (ICL), is the first enzyme of glyoxylate pathway. In pathogenic Mtb H37Rv, two types of ICLs have been reported - ICL1 encoded by icl (Rv0467) is well characterized and homologous to eubacterial enzyme whereas ICL2 encoded by aceA is more related to eukaryotic isocitrate lyase. To compound it, the aceA gene is split into two ORFs namely $r v 1915 / a c e A a$ and $r v 1916 / a c e A b$. No translational product or function has been reported for the later and therefore, in vivo existence of Rv1916 is debatable. This study reports recombinant production of Rv1916 in heterologous host E. coli BL21 (DE3) for structure function studies. The studies categorically demonstrate that akin to Mtb ICL1, recombinant Rv1916/ICL2b also possess dual ICL and methylisocitrate lyase (MICL) activities in vitro. Further, based on in silico analysis, a putative function linked to secondary metabolite synthesis is assigned to the unique mycobacterial domain IV.

Keywords: Isocitrate lyase, Methylisocitrate lyase, Rv0467, Cloning, Purification, Catalytic activity, Bioinformatics, Phylogenetic analysis 


\section{Introduction}

According to the World Health Organization, Tuberculosis (TB), a disease caused by Mycobacterium tuberculosis (Mtb), is amongst top 10 causes of death worldwide. Despite the availability of DOTS (Directly observed treatment, short-course) chemotherapy and vaccine against tubercle bacilli, in the year $2017, \sim 1.3$ million deaths occurred and $\sim 1.7$ billion population globally was reported to be infected with latent bacteria [1]. This latent bacterium persists inside the infected tissues of the host in an inactive form and remains resistant to standard TB regimen. This subpopulation gets reactivated as the immunity of the host wanes due to chronic stress, poor diet and certain infection such as HIV infection or through ageing. Therefore, it is of vital importance that risk of active TB disease ensuing in $\sim 23 \%$ of the world population is reduced by developing new diagnostics, therapeutics and vaccines against this latent form of $M t b$. This can only be achieved by better understanding of biochemical pathways employed by the bacterium for establishing latency or resuscitation. Some known pathways responsible for persistence are: stringent response [2], toxin-antitoxin modules [3], efflux pumps [4], energy metabolism and ATP production [5]. The environmental niche for Mtb within human host is the lipid rich macrophage which facilitates survival and/or persistence of pathogen by providing nutrients. Therefore, genes involved in fatty acid (FA) metabolism are essential for maintaining chronic infection in the host. Glyoxylate shunt is one such pathway which is functional in bacteria, fungi, plants and nematodes and allows the utilization of even-chain FA or C2 compounds for carbon assimilation and anaplerosis. This two-step pathway involves hydrolysis of isocitrate (C6 compound) to succinate (C4 compound) and glyoxylate (C2 compound) by the enzyme ICL followed by condensation of acetyl-CoA ( $\mathrm{C} 2$ compound) with glyoxylate to produce malate ( $\mathrm{C} 4$ compound) by Malate synthase (MS) [6,7]. Role of glyoxylate cycle is well documented in virulence of bacterial and fungal pathogens [8]. Upregulation of Mtb ICL as observed by proteomics [9] and 
transcriptomics [10] approaches in response to phagocytosis is indicative of its role in infection. Apart from role in glyoxylate cycle, researchers assign other functions to $M t b$ ICL in conferring resistance to a variety of stresses (such as hypoxia and starvation)and tolerance to most commonly used antibiotics for instance isoniazid, rifampicin and streptomycin [1113]. Its role as methylisocitrate lyase (MICL), an enzyme in the methylcitrate cycle which is involved in the metabolism of odd-chain FA, is also well established [14-16].

In many bacterial species including Mycobacterium, two ICLs are present - ICL1 ( 48 kDa) is prokaryotic isoform whereas ICL2 $(\sim 85 \mathrm{kDa})$ is eukaryotic-like [17]. Noticeably, in the most common pathogenic Mtb H37Rv lab strain, the gene icl2/aceA is split into aceAa and $a c e A b$ which encodes for Rv1915 ( 40.5kDa) and Rv1916 ( 45 kDa) respectively. Knock out studies carried out with $\Delta i c l 1$ and $\Delta i c l 2$ of $M t b$ (Erdman), showed clearance of bacterium from lungs of infected mice, demonstrating role of both the ICLs in Mtb pathogenicity [18]. Therefore, discovery of inhibitors that target both the ICLs of Mtb is the need of the hour for developing effective antimycobacterials against persistent-stage $M t b$.

To briefly review structure function related studies of Mtb ICLs, crystal structures of ICL1 (PDB IDs: 1F61, 1F8I, 1F8M, 6C4A and 6C4C) have extended our understanding of this important assimilatory enzyme [19]. Biological relevant form of Mtb ICL1 is tetrameric (dimer of dimers) where C-terminal helix-swapping between two adjacent subunits is responsible for stabilizing the dimers. Basic subunit adopts a triosephosphate isomerase (TIM) barrel fold comprising of $8 \alpha$-helices and $8 \beta$-strands where the active site is located at the C-terminal end of the barrel in a flexible loop (residues 185-196 in Mtb ICL1). This active site loop functions as a gate by virtue of undergoing conformational change leading to "open" or "closed" active site. Presence of $\mathrm{Mg}^{2+}$ cofactor is crucial for ICL activity as it stabilizes the transition state. [19-21]. A recent study reports crystallography analysis and 
inhibition of $M t b$ ICL1 and ICL2 by 2-vinyl-D-isocitrate (PDB ID: 5DQL) advocating mechanism-based inactivators of target enzyme over competitive inhibitors [22].

As stated earlier, Mtb ICL1 functions in the methylisocitrate cycle also as MICL. $\mathrm{K}_{\mathrm{m}}$ values for the two substrates have been reported to be $0.19 \mathrm{mM}$ for isocitrate and $0.72 \mathrm{mM}$ for methylisocitrate, the smaller $\mathrm{Km}$ indicating higher affinity for the former substrate [14]. Based on the comparison between crystal structure of Mtb ICL1 C191S mutant complexed with pyruvate and succinate (reaction products of MICL) and the structures of Mtb ICL1 with glyoxylate (PDB ID: 1F8I) as well as E. coli MICL (PDB ID:1XG3), it was concluded that the active site of $M t b$ ICL1 can accommodate extra methyl of pyruvate without much perturbation. Also, the differences in the respective active sites for isocitrate and methylisocitrate may be attributed to three conserved amino acid substitutions namely W283, F345 \& T347 in Mtb as opposed to equivalent F186, L234 and P236 in the E. coli MICL [14]. The MICL activity of ICL1 is essential for Mtb to survive on propionate and hence it is imperative to target both the activities of Mtb ICLs.

Above research studies have focused on $M t b$ ICL1, but not much information, either structural or biochemical, is available for eukaryotic-like Mtb ICL2. Intriguing questions that need to be addressed with respect to H37Rv Mtb ICL2 (split into two separate gene products, referred henceforth as Rv1915 or ICL2a and Rv1916 or ICL2b for consistency with ICL nomenclature) are - (i) Though Mtb ICL2b/Rv1915 has ICL activity, is ICL2b/Rv1916 a functional gene product of $a c e A b$ as well? (ii) An extended C-terminal domain IV in ICL2b appears to be unique to mycobacteria and has not been identified so far in other ICL2s [18]. What could be the role of this domain IV in ICL2 $b$ ? With this backdrop, recombinant version of Rv1916/ICL2b has been produced in E. coli and investigated for ICL/MICL activity. For comparative purposes, recombinant $M t b$ Rv0467 has also been cloned, expressed and purified likewise. This study demonstrates that although the activity is much lower than the main 
ICL1/Rv0467, recombinant ICL2b is able to catalyse both isocitrate and methylisocitrate substrates, suggesting it is both active and structured. In addition, based on homology with Streptomyces glaucescens Tetracenomycin F2 Cyclase, a putative function for the unique domain IV is being ascribed in secondary metabolite production.

\section{Materials and Methods}

\subsection{Materials}

Genomic DNA of Mycobacterium tuberculosis H37Rv, Phenylmethylsulfonylfluoride (PMSF) and Ethylenediaminetetraacetic acid (EDTA) were purchased from Hi-media laboratories. Taq polymerase and Pfu polymerase were procured from G-Biosciences. Restriction endonucleases NheI and HindIII were purchased from Fermentas. Strep Tactin Resin and Desthiobiotin were procured from IBA Lifesciences. DL-Isocitric acid, Phenylhydrazine and 3-Nitropropionate (3-NP) was bought from Sigma (India). 2methylisocitrate has been synthesized and monitored by $1 \mathrm{H}$ NMR as per the step wise described protocol of Munoz-Elias et al., 2006 who modified the methods of Plaut et al., 1975; Brock et al., 2001 [23-25].

\subsection{Sequence extraction, Phylogenetic analysis and Structure Prediction}

In order to deduce the evolutionary relationship of Rv1916 with other ICLs, different type of ICL proteins were identified by BLASTP program. The protein sequences of representative ICLs were retrieved from RefSeq database. These sequences were represented by the nomenclature of KEGG database (https://www.genome.jp/kegg/genes.html) to list the name of species of sequence along with protein identifiers. The sequences which are not found in KEGG database were named as "Sob" (represents the Soil bacteria). The phylogenetic tree was generated using Molecular Evolutionary Genetics Analysis (MEGA) software version 10.0.5 using neighbour-joining method [26]. Secondary structure of Rv1916 was predicted using ESPript 3.0 [27]. Thereafter, homology model of Rv1916 was generated using I- 
TASSER [28]. Unaligned region of Rv1916 (236-398) were searched against the Protein Data Bank (PDB) database using BLASTP program.

\subsection{Cloning and Expression of Rv1916}

Mycobacterium tuberculosis H37Rv gene encoding Rv1916 (genomic DNA purchased from Hi-media laboratories) was cloned in pET21c expression vector using standard protocols as described by Sambrook and Russell [29] for all DNA manipulations. The forward 5'gatttagctagcacctacggagaggccgtg-3, and $3^{\prime}$ ' gatttaaagcttattattttcgaactgcgggtggctccaagcgctcgcetccttcgtgatcaacttccg-3' primers (synthesized through Eurofins Genomics India Pvt. Ltd) included the underlined NheI and HindIII restriction sites respectively. A strep-tag was built in the reverse primer for ease in purification. Positive clones were screened by colony PCR with gene specific primers and verified by double digestion of the recombinant construct with NheI and HindIII restriction enzymes (Thermo Fisher Scientific). The nucleotide sequence of the cloned gene was further verified by Sanger sequencing (Eurofins Genomics India Pvt. Ltd) using standard primers for T7 promoter and terminator. For expression of Rv1916, E. coli BL21(DE3) was transformed with the recombinant DNA plasmid followed by culturing a colony in $3 \mathrm{ml}$ LB media supplemented with ampicillin $(100 \mu \mathrm{g} / \mathrm{ml})$ with shaking at $180 \mathrm{rpm}$ overnight at $37{ }^{\circ} \mathrm{C} .1 \%$ of this overnight culture was inoculated into fresh $3 \mathrm{ml} \mathrm{LB}$ media with antibiotic and incubated in similar conditions for $\sim 3$ hrs. Expression of recombinant protein was induced by adding 1 mM IPTG and continuing incubation with shaking at $30{ }^{\circ} \mathrm{C}$ for 3 hours. After induction, culture was divided into two microfuge tubes and cells harvested by centrifugation at maximum speed for 5 minutes at $4{ }^{\circ} \mathrm{C}$. For analysis of over expression in total cell lysates (TCLs), the cell pellet of induced/uninduced cultures was resuspended in $50 \mu 1$ of 1X SDS loading dye $(50 \mathrm{mM}$ Tris-HCl, pH 6.8; $1 \% \beta$-mercaptoethanol; $1 \%$ SDS; $10 \%$ glycerol; 0.04\% bromophenol blue), boiled and subjected to 10\% SDS PAGE. But for checking the 
localization of expressed protein in the soluble/insoluble fraction of the lysate, the cell pellet was resuspended in $100 \mu \mathrm{l}$ of lysis buffer containing: $50 \mathrm{mM}$ Tris $\mathrm{pH} 8.0,150 \mathrm{mM} \mathrm{NaCl}, 1$ mM EDTA, $2 \mathrm{mM} \beta$-Mercaptoethanol and 1mM PMSF, incubated on ice for 10 minutes and lysed by sonicating the cell suspension (10 $\mathrm{sec}$ On $30 \mathrm{sec}$ Off for total $10 \mathrm{~min}$ ) using Ultrasonic Water Bath sonicator. Insoluble fraction/cell debris as well as soluble fraction/supernatant were collected after centrifugation at $12,000 \mathrm{rpm}$ at $4^{\circ} \mathrm{C}$ for $20 \mathrm{~min}$, boiled with $1 \mathrm{X}$ SDS loading dye before electrophoresis on $10 \%$ SDS polyacrylamide gel. ImageJ software (BioRAD) was used to quantify the protein bands from SDS-PAGE Gel.

\subsection{Purification of Rv1916}

The recombinant Rv1916 was purified using Strep-Tactin affinity procedure. Briefly, cell pellet of $250 \mathrm{ml}$ culture was resuspended in $30 \mathrm{ml}$ of lysis buffer $(50 \mathrm{mM}$ Tris $\mathrm{pH} 8.0,500$ $\mathrm{mM} \mathrm{NaCl}, 1 \mathrm{mM}$ EDTA, $2 \mathrm{mM} \beta$-Mercaptoethanol and 1mM PMSF) and the cells were lysed by sonication using Vibra Cell VCX 130 sonicator for 20 minutes with a pulse of 10 seconds on and 10 seconds off. After lysis, cell debris were removed by centrifugation at $12000 \mathrm{rpm}$ for an hour and supernatant was filtered through a $0.45 \mu \mathrm{M}$ filter. The clear lysate thus obtained was applied on $1 \mathrm{ml}$ of Strep-Tactin sepharose resin (IBA Lifesciences) equilibrated with lysis buffer. After binding, the column was washed with $10 \mathrm{ml}$ of wash buffer (same as lysis buffer). The recombinant Rv1916 was eluted from the column with elution buffer with $2.5 \mathrm{mM}$ Desthiobiotin (IBA Lifesciences) and concentration estimated by Bradford protein assay. For most downstream applications, the pure fractions were pooled and dialyzed in storage buffer (20 mM Tris $\mathrm{pH} 8.0,100 \mathrm{mM} \mathrm{NaCl}$ and $5 \%$ glycerol) before aliquoting and freezing at $-80{ }^{\circ} \mathrm{C}$. For gel filtration chromatography on HiLoad 26/60 Superdex 200 prep grade column (GE Healthcare), the eluted fractions were pooled and concentrated with Amicon stirred cell (using 10kDa ultrafiltration membrane) to a final 
concentration of $\sim 2 \mathrm{mg} / \mathrm{ml} .10 \mathrm{ml}$ of this sample was loaded on column pre-equilibrated with storage buffer for oligomeric analysis.

\subsection{Two-Dimensional Gel Electrophoresis (2DE)}

The experiment was done in three phases; rehydration, isoelectric focusing (IEF) and Seconddimension i.e. SDS PAGE analysis. For Isoelectric focusing (IEF), broad range (pH 3-10, $11 \mathrm{~cm}$ ) linear immobilized $\mathrm{pH}$ gradient (IPG) strips were utilized. Prior to IEF, overnight rehydration of IEF strips was carried out and a total of $150 \mu \mathrm{g}$ of protein sample was rehydrated in $2 \mathrm{ml}$ of rehydration buffer containing: $50 \mathrm{mM}$ DTT, $7 \mathrm{M}$ urea, $2 \mathrm{M}$ thio-urea, 2\% CHAPS, $0.2 \%$ Bio-Lyte and trace of Bromophenol blue. Subsequently, IEF was carried out in PROTEAN IEF cell (Biorad) for 24,000 volts hours (VhT) at $20{ }^{\circ} \mathrm{C}$. After completion, the IPG strip was first equilibrated with $2 \mathrm{ml}$ of equilibration buffer I $(0.37 \mathrm{M}$ Tris- $\mathrm{HCl} \mathrm{pH} 8.8$, $6 \mathrm{M}$ urea, $20 \%$ glycerol, $2 \%$ DTT and 2\% SDS), followed by equilibration buffer II $(0.37 \mathrm{M}$ Tris- $\mathrm{HCl} \mathrm{pH} 8.8,6 \mathrm{M}$ urea, 20\% glycerol, 2.5\% Idoacetamide and 2\% SDS) for 20 minutes. Second-dimension electrophoresis was carried out in PROTEA- IIxi gel apparatus (Biorad) on a $12.5 \%$ polyacrylamide gel $(16 \times 20 \mathrm{~cm})$ with 80 volts, until the bromophenol blue came out of the gel.

\subsection{ICL, MICL activity and inhibition assays}

Activity assays were performed as described by Dixon and Kornberg [30] with some modifications. The reaction mixture contained $50 \mathrm{mM}$ MOPS pH 7.0, $6 \mathrm{mM} \mathrm{MgCl}, 4 \mathrm{mM}$ Phenylhydrazine- $\mathrm{HCl}$, and different concentrations of either isocitrate (Sigma India) or 2methylisocitrate [16]. The reaction was initiated by adding $20 \mu \mathrm{l}$ (5 $\mu \mathrm{g}$ for ICL activity and $25 \mu \mathrm{g}$ for MICL activity) of purified enzyme in $980 \mu 1$ of reaction mixture and increase in absorbance due to formation of glyoxylate or pyruvate phenylhydrazone was monitored at $324 \mathrm{~nm}$. To compare the activities of Rv1916 and Rv0467, a similar set of reaction mixture was prepared and the reaction was carried out with $2 \mu \mathrm{g}$ (ICL activity) and $10 \mu \mathrm{g}$ (MICL 
activity) of purified recombinant Rv0467. Inhibition of both activities of Rv1916 by 3-NP, a reaction intermediate analogue and a known inhibitor of ICL was also assessed. For inhibition assay, the enzyme was incubated with $2 \mu \mathrm{M}$ of 3 -NP for 30 seconds and reaction was initiated by adding different concentrations of either isocitrate or 2-methylisocitrate to the reaction mix and product formation monitored as stated above for the activity assay.

\section{Results}

\subsection{Phylogenetic, Sequence analysis and Molecular modeling of Rv1916}

BLASTP search of Rv1916 against the NCBI non-redundant database resulted in the identification of different types of ICLs with varying sequence length of the protein. Representative members of each group of ICL were selected to perform the phylogenetic analysis. Phylogenetic tree point to the diversity between different ICLs even if within the same organism. Rv0467, Rv1915 and Rv1916, ICLs of Mtb, lie in different clades, with Rv1916 evolutionarily closer to the ICLs of soil bacteria (Fig. 1).

Structure based multiple sequence alignment of Rv1916 was carried out with other ICL superfamily members that either catalyse $\mathrm{C}-\mathrm{C} / \mathrm{P}-\mathrm{C}$ bond formation or cleavage and include eukaryotic and prokaryotic ICLs, MLL9387 (putative phosphoenolpyruvate hydrolase), DFA0005 (superfamily member with binding pocket for $\alpha$-ketoglutarate), OAD (oxaloacetate decarboxylase), MICL (2-methylisocitrate lyase), PDP (petal death protein), DMML (2R,3Sdimethylmalate lyase), OAH (oxaloacetate acetyl hydrolase) and KPHMT (Ketopantoate hydroxymethyl transferase). Table S1 presents percentage identity, similarity and query coverage for pairwise sequence alignment of Rv1916 with ICL superfamily members. Although only $\sim 235$ residues of Rv1916 aligned ( $\sim 160$ residues unaligned), best sequence similarity is evident with eukaryotic (57\% similarity, $69 \%$ query coverage) and prokaryotic (62\% similarity, 59\% query coverage) ICLs. Sequence mapping of all three Mtb ICLs on eukaryotic homolog from A. nidulans in Fig. 2A help in emphasizing the following key 
features of these $M t b$ isoforms - (1) ICL signature motif KKCGH is present in Rv0467, Rv1915 and ICL of A. nidulans but not in Rv1916, although other important active site residues (E91, N119, S212, T154 and Q159) which are conserved in all ICLs are present in Rv1916 as well. (2) An insertion corresponding to domain II in A. nidulans (residues 267363) is present in both Rv1915 and Rv1916 but not in Rv0467. This domain is explicitly observed in plants and fungal ICLs and is responsible for translocating ICL into the peroxisomal microbodies [31]; (3) An extended region at the C-terminus of Rv1916 ( 160 residues corresponding to domain IV) is only present in Rv1916 and not in Rv0467, Rv1915 and $A$. nidulans. Interestingly, BLASTP search of this domain with non-redundant database (excluding Mycobacteriaceae family) disclosed the presence of domain IV in the ICLs of some other bacterial species namely, Gemmatimonadetes, Verrucomicrobia, Acidobacteria, etc. These bacteria although prevalent in diverse environments are especially abundant in soils, but under-represented in cultures. Due to advances in cultivation techniques, it is becoming possible to isolate these uncultivable bacteria for research studies and molecular analysis [32-34]. Consequently, sequences of some species from these rare phyla have start appearing in protein databases.

Further, search with the same query sequence of domain IV against the PDB database registered a hit with 109 amino acid long Streptomyces glaucescens Tetracenomycin F2 Cyclase (PDB ID: 1TUW) showing 30\% identity and 58\% similarity. Fig. 2B presents the pairwise sequence alignment of Rv1916 with PDB ID: 1TUW and its closest homologue from A. nidulans (PDB ID: 1DQU). The N-terminal 1-235 residues of Rv1916 align with 1DQU whereas 253-386 residues partially align with 1TUW and 16 residues (236-252) remain unaligned. Based on the sequence and structure alignment, secondary structure for Rv1916 has been predicted using 1DUQ and 1TUW as a template (Fig. 2B). The result indicates that Rv1916 is mainly composed of $18 \alpha$-helices and $10 \beta$-sheets. A three- 
dimensional model of Rv1916 has also been generated using I-TASSER server with the Cscore of -3.09 (Fig. S2). The C-score value represents the confidence score of the predicted model and is acceptable within -5 to 2 (Table S4).

\subsection{Cloning, Expression and purification of Rv1916}

The construction of recombinant pET21c-rv1916 clone was confirmed by fall out of $\sim 1.2 \mathrm{~kb}$ gene after double digestion with the enzymes used for cloning (Fig. S1). Analysis of induction of recombinant Rv1916 in E. coli BL21 (DE3) cells with $1 \mathrm{mM}$ IPTG at $30{ }^{\circ} \mathrm{C}$, exhibit expression of recombinant protein corresponding to expected size of $\sim 47 \mathrm{kDa}$ on SDS- polyacrylamide gel. Further, $\sim 55 \%$ of over expressed recombinant protein is localized in the insoluble fraction of the lysate (Fig. 3A). The expressed protein was purified by StepTactin affinity chromatography as per standard protocols to $\sim 85 \%$ purity with yields of $\sim 5$ $\mathrm{mg} / \mathrm{l}$ of culture pellet (Fig. 3B). Multiple light bands just below the major band are indicative of protein degradation or contamination (lanes 6 and 7, Fig. 3B). Further, Gel filtration chromatography (GFC) was carried out for determining the molecular weight of biologically relevant form of the protein with pooled strep-tactin elutes. The chromatogram illustrates (Fig. 3C) - (i) major population exists as high molecular weight aggregates, (ii) a significant population corresponds to monomer size and (iii) population with lower than subunit molecular weight suggests impurity or degradation. Concentration of GFC purified fractions resulted in precipitation and concentration of soluble protein could not be achieved beyond 2 $\mathrm{mg} / \mathrm{ml}$. Due to losses involved in carrying out GFC and protein concentration, affinity purified protein after dialysis in storage buffer and concentrations ranging from 0.5 to 1 $\mathrm{mg} / \mathrm{ml}$, was considered good enough for all further characterizations.

\subsection{Two-Dimensional Gel Electrophoresis (2DE)}

Determination of molecular weight and $\mathrm{pI}$ of a protein by $2 \mathrm{D}$ electrophoresis is an essential aspect of molecular characterization of a new protein. The knowledge of a prior information 
of accurate $\mathrm{pI}$ also helps in buffer optimization for protein purification and improvement in protein solubility. 2DE of Rv1916 reveals an isoelectric point of $\sim 6.6$, suggesting acidic character of the protein (Fig. 3D). Based on this information, all downstream steps of cell lysis and protein purification were carried out at $\mathrm{pH}$ 8. Although, the second dimension for molecular weight identification cannot discuss the presence or absence of higher order oligomeric forms (due to denaturing nature of SDS PAGE), but in any case subunit molecular weight of $\sim 47 \mathrm{kD}$ deduced from the $2 \mathrm{DE}$ corroborates with Coomassie Brilliant Blue stained SDS PAGE analysis (Fig. 3A and B). Further, a single dot on the 2D gel also assures homogeneous sample preparation of Rv1916 without the presence of any other charged isoforms of the protein (Fig. 3D).

\subsection{Enzyme Kinetics of recombinant Rv1916 and Rv0467}

ICL and MICL activities of both Rv1916 and Rv0467 were monitored under identical assay conditions and kinetic parameters were computed using Lineweaver-Burk double reciprocal plot (Fig. 4; Table 1). The $\mathrm{K}_{\mathrm{m}}$ of recombinant ICL2b for isocitrate substrate is $\sim 13 \mu \mathrm{M}$, 4-fold higher than that of ICL1 $(\sim 3.25 \mu \mathrm{M})$, indicating higher concentration of isocitrate is required by the former to reach comparable $\mathrm{V}_{\max }$ under similar set of conditions. Although, as opposed to Rv0467 (2 $\mu \mathrm{g})$, 5-fold excess of Rv1916 (10 $\mu \mathrm{g})$ has been used in the assay, but this is not expected to affect $\mathrm{K}_{\mathrm{m}}$ since Michaelis constant is independent of enzyme concentrations. 20fold lower catalytic efficiency of ICL2 $b$ for isocitrate is observed when compared to ICL1 $\left(0.53 \mu \mathrm{M}^{-1} \min ^{-1}\right.$ against $\left.9.5 \mu \mathrm{M}^{-1} \mathrm{~min}^{-1}\right)$. Interestingly, the difference in preference for methylisocitrate substrate is not so obvious between the two enzymes ( $\mathrm{K}_{\mathrm{m}}$ being $300 \mu \mathrm{M}$ against $241 \mu \mathrm{M}$ ) and difference in turn over $\mathrm{K}_{\text {cat }} / \mathrm{K}_{\mathrm{m}}$ is also 10 -fold (Table 1).

The inhibition of ICL and MICL activities of Mtb ICL2 $b$ with 3-NP, an established inhibitor routinely used as a control in ICL inhibition assays, was also investigated. The LineweaverBurk double reciprocal plot (Fig. 4) includes the ICL (Fig. 4A) and MICL (Fig. 4B) 
inhibition of Rv1916 by 3-NP (filled circles). Although data has been acquired at a single concentration of inhibitor, reduced $\mathrm{K}_{\mathrm{m}}$ and $\mathrm{V}_{\max }$ in both cases is unambiguous, suggesting uncompetitive inhibition. The inhibition constant $\mathrm{K}_{\mathrm{i}}$ determined from the plot corresponds to 7.9 $\mu \mathrm{M}$ and $135.5 \mu \mathrm{M}$ for ICL and MICL activities respectively (Table 1). Inhibition experiments performed under similar conditions for Rv0467 corroborate with previous reports, which shows that $3-\mathrm{NP}$ is a competitive inhibitor of isocitrate substrate, as $\mathrm{K}_{\mathrm{m}}$ is increased but $\mathrm{V}_{\max }$ is unchanged. The $\mathrm{K}_{\mathrm{i}}$ of $7.4 \mu \mathrm{M}$ is higher than that of $3 \mu \mathrm{M}, 17 \mathrm{nM}$ reported for ICL from Mycobacterium tuberculosis CSU93 and Pseudomonas indigofera respectively $[35,36]$. The observations for inhibitory potential of 3-NP for MICL activity of Rv0467 is somewhat interesting as the time dependent plot displays slow inhibition (Fig. 4D inset). Due to errors associated with determination of initial velocities for Lineweaver-Burk plot in this case, it is difficult to discuss nature of inhibition for MICL activity of Rv0467 and compute $\mathrm{K}_{\mathrm{i}}$. Nevertheless, slight reduction in $\mathrm{V}_{\max }\left(0.85 \mu \mathrm{M}\right.$ min $^{-1}$ against $0.74 \mu \mathrm{M}$ min $\left.^{-1}\right)$ but no change in $\mathrm{K}_{\mathrm{m}}$ (Fig. 4D) is suggestive of non-competitive inhibition.

\section{Discussion}

Despite global efforts to eliminate $M t b$, the pathogen continues to infect approximately one in three people due to its ability to survive within the hostile and nutrient deprived environment of host macrophages, its privileged niche, for an indefinite period. This is due to microbe's capability to escape host innate immune responses by inhibiting phagocytosis, apoptosis, autophagy and phagosome lysosome maturation of macrophages or evade adaptive immune response through antigenic variation that influences recognition and avoids killing of the pathogen [37]. These processes are realized with the help of pathogen's virulence factors which are typically effector proteins or other molecules synthesized by enzymes. Understanding functionality of these players is critical to decoding their essentiality for Mtb in establishing and maintaining infection. 
The gate enzyme ICL of glyoxylate cycle is essential for Mtb's adaptation and metabolic reprogramming during progression of infection from replicative to non-replicative stage. Three ICL encoding genes are present in Mtb H37Rv. Phylogenetic analysis reveal all three to reside in different clads wherein $M t b$ Rv1916/ICL2 ${ }_{b}$ appears to be more related to soil bacteria (Fig. 1). This observation agrees backed up by the fact that though domain IV of ICL2 has been reported to be unique to mycobacterial species [18], this study has uncovered the presence of this domain in ICLs of soil bacteria as well (Table S2). ICLs from most of these bacteria are uncharacterized, but they contain the conserved ICL/PEPM_KPHMT domain (Table S2). Intriguingly, like $M t b$, these soil bacteria are also reported to be slow growers and able to utilize a wide range of carbon compounds, a feature suggestive of broad metabolic capability and a lifestyle suitable for adaptation to low nutrient environment [3840].

Different members of ICL/PEPM_KPHMT enzyme superfamily have diverse functions [41]. Pairwise sequence alignment of Rv1916 with each member show highest homology with eukaryotic as well as prokaryotic ICLs. This study confirms the ICL activity of Rv1916 despite absence of ICL signature motif - KKCGH (Fig. 2A). Deviation from the motif is also observed in $P$. aeruginosa ICL where the sequence is KQCGH and a consensus sequence $\mathrm{QIENQ}_{\mathrm{IS}} \mathrm{VE}_{\mathrm{K}} \mathrm{QCGHQD}_{\mathrm{C}}$ is anticipated for ICL catalytic activity and thermo stability $[42,43]$. Notably, a similar pattern $\left({ }^{14} \mathrm{QSEGE}^{19}\right)$ present at the N-terminus of Rv1916, along with other conserved active site residues may be responsible for its catalytic activity. In fact, the Rv1916 model generated through I-TASSER server, using 1DUQ as the template (Fig. S2), predicts ligand binding site/catalytic centre residues of the enzyme to be E91, N119, S121, S123 and T154 with C-score of 0.21 (Table S4). This is in complete agreement with the active site residues that have been mapped in Fig. 2A (based on residues reported in literature for other ICLs) and fosters confidence in the generated model. Needless to say mutagenesis 
studies need to be employed for validation and clarification of the catalytic mechanism of this enzyme. Additionally, the work carried out in the study unequivocally demonstrate MICL activity associated with ICL2b suggesting role in odd chain fatty acid metabolism akin to dual role of $M t b$ ICL1. Evaluation of $\mathrm{K}_{\mathrm{cat}} / \mathrm{K}_{\mathrm{m}}$ for relative catalytic efficiency between the two $M t b$ ICLs, reveals 20 -fold reduced efficiency of ICL2 $b$ for isocitrate $\left(0.53 \mu \mathrm{M}^{-1} \mathrm{~min}^{-1}\right.$ versus 9.5 $\left.\mu \mathrm{M}^{-1} \min ^{-1}\right)$ and $\sim 10$ times lower for methylisocitrate $\left(0.004 \mu \mathrm{M}^{-1} \min ^{-1}\right.$ versus $0.033 \mu \mathrm{M}^{-1}$ $\left.\min ^{-1}\right)$. It is quite possible that absence of optimum signature sequence may result in lower ICL activity compared to Rv0467 (Fig. 4). Inhibition studies of Rv1916 with 3-NP, a nitro analogue of succinate, provides evidence that the inhibitor is uncompetitive for both substrates ( $\mathrm{K}_{\mathrm{m}}$ as well $\mathrm{V}_{\max }$ are reduced). This draws upon the supposition that binding of the inhibitor to Rv1916-substrate complex promotes substrate binding to the enzyme, rationalizing reduced $\mathrm{K}_{\mathrm{m}}$. But since $\mathrm{V}_{\max }$ is also reduced, it insinuates that the catalysis of enzyme-substrate to product formation is sluggish probably because substrate is locked effectively by the inhibitor.

Rv1916 appears to be closer to eukaryotic homolog (A. nidulans) rather than prokaryotic homolog (Rv0467) because of the presence of domain II (Fig. 2A). This domain is known to aid in compartmentalizing the enzyme to peroxisomes which have a vital role in $\beta$-oxidation of long chain fatty acids permitting growth of some organisms on non-fermentable carbon sources [44] and detoxification of reactive oxygen species [45]. Presence of this domain in 1916 makes one speculate, if this eukaryotic like ICL is involved in survival of the pathogen inside host macrophages via interaction with peroxisomes, akin to activation of peroxisome proliferator-activated receptor $\gamma(\operatorname{PPAR} \gamma)$ by Leishmania that promotes its survival in host macrophages [46].

Structurally, domain IV of Rv1916 appears to be related to Tetracenomycin F2 Cyclase, a member of multidomain enzyme family of polyketide synthase known to synthesize 
secondary metabolites. These secondary metabolites are reported to play important role in (1) survival of $M t b$ in oxygen depleted environment by serving as an alternate intermediate electron carrier such as Polyketide Quinones [47] and (2) halting the cell cycle of macrophages at G0-G1 phase for prolonged survival of Mtb during its persistence [48]. Investigation of co-occurrence of genes in the neighbourhood of Rv1916 and tetracenomycin F2 cyclase suggest a common functional association between the listed genes (Table S3A and B) and compels to hypothesize secondary metabolite production as a possible function for this fascinating $M t b$ H37Rv Rv1916/ICL2b.

Recombinant $M t b$ Rv1916/ICL2b was produced in heterologous E. coli host for functional characterization. Purity in preparation is evident from single band on Coomassie Brilliant Blue stained SDS-PAGE and single spot on 2-DE (Fig. 3). These molecular techniques for analysing proteins, establish subunit molecular weight of Rv1916 to be $\sim 47 \mathrm{kDa}$ and $\mathrm{pI}$ to be 6.6, in concordance with $46.5 \mathrm{kDa} \mathrm{MW}$ and $6.2 \mathrm{pI}$ computed with Expasy tool (https://web.expasy.org/compute_pi/). Subunit analysis by GFC indicates Rv1916 to be a monomer (Fig. 3C), unlike Rv0467 and eukaryotic A. nidulans ICLs which are tetramers In A. nidulans ICL, Y76 and L91 - N-terminal residues of one subunit interact with F471, Y475, M480 and Y483 - C-terminal residues of the adjacent subunit (PDB ID: 1DQU). Similarly, in Rv0467, structurally equivalent residues involved in subunit interactions are L69 and N75 from one partner and Y365, N355 and F351 from the other (PDB ID: 1F8I). As corresponding $\mathrm{N}$ - terminal residues are not present in Rv1916, the subunit interactions is likely to be disturbed and may explain the monomeric existence of Rv1916 as observed by GFC. Alternative approaches such as analytical ultracentrifugation sedimentation equilibrium need to be attempted, but since Rv1916 appears to be prone to concentration dependent aggregation/precipitation and not amiable to long term storage as opposed to stable Rv0467, first and foremost these obstacles need to be tackled. Then again, it is very much possible that 
these ICL2s are not stable, as recombinant M. tuberculosis CSU93 AceA, a gene product of single ORF, is also reported to be unstable [36].

ICL and MICL activities for Rv1916 and Rv0467 carried out under identical conditions categorically establish that Mtb Rv1916/ICL2b possesses in vitro ICL and MICL activity, hence has dual activity similar to that reported for Mtb Rv0467/ICL [14]. Although compared to $M t b$ Rv0467, the Mtb Rv1916/ICL2b has much lower ICL and MICL activity. Reduced catalytic efficiency of ICL2 in comparison with ICL1 has been reported earlier for both the substrates $[14,36]$ but these studies are not carried with split version of ICL2. Inhibition of Rv1916 ICL and MICL activity was investigated with prototype ICL inhibitor 3-NP and revealed inhibition (Fig.4A-D). Both ICL and MICL activities have been reported to be critical in Mtb Erdman strain where ICL2 (766 amino acid long version corresponding to 85 $\mathrm{kDa}$ ) is coded by intact ace $A$ gene. This study demonstrates that despite being split version of ICL2 where ICL signature sequence is deviated, Rv1916/ ICL2b is a bifunctional enzyme in vitro, with anticipated role in acetyl-CoA metabolism (as ICL) and propiony-CoA metabolism (as MICL) in Mtb. Because of presence of domain IV in mycobacterial ICL2s, additional function in secondary metabolite synthesis is foreseen suggesting multifaceted role of this ICL2 isoform. Evolutionary relationship with newly identified soil bacteria (Acidobacteria, Verrucomicobia and Gemmatimonadetes) that produces diverse polyketide and non-ribosomal peptide biosynthetic gene clusters [49] lend weight to proposed role but may be dependent on intracellular environment. Functional studies and elucidation of 3-D structure are necessary to verify the proposed role of this fascinating target in pathogenicity of $M t b$.

\section{Conclusion}

This study is a first report of Rv1916/ICL2b possessing dual ICL and MICL activities in vitro. Existence of translational product of the $r v 1916 / \mathrm{icl} 2_{b}$ gene has been questionable till date but 
this work resolves the dilemma and provides evidence that although Rv1916 does not possess the $\mathrm{N}$ terminal domain encompassing the signature sequence of ICL, it is structured enough to exhibit unambiguous ICL and MICL activities in vitro. Comparison of catalytic efficiency with Rv0467, reveal 20-fold and 10-fold lower turnover rate for isocitrate and methylisocitrate substrates respectively. Further, inhibition assays with known inhibitor 3NP, suggests uncompetitive binding to Rv1916-substrate complex for both the substrates. The study also draws attention of the scientific community to the fact that the extended domain IV of ICL2 from mycobacteria, considered unique to this species, is present in the ICLs of some soil bacterial species, rendering Rv1916/ICL2 ${ }_{b}$ closer to these species evolutionarily. A I-TASSER server generated complete model of Rv1916 helps in hypothesizing a putative role for domain IV of Rv1916 in secondary metabolite synthesis.

\section{Acknowledgements}

VG would like dedicate this work to the memory of Dr. Chittaranjan Rout, whose research insights initiated, assisted and expanded this research. Although no longer with us, his beliefs continues to encourage to pursue this challenging work. Authors gratefully acknowledge support from Indian Council of Medical Research (ICMR), Govt. of India through research grant BIC/12(16)/2012) without which these studies would not have been possible. MA would like to thank DST, Govt. of India for INSPIRE fellowsip and contingency grant and Ms. Sunita Gupta for her valuable help in building and analysing the models of Rv1916. JS is a recipient of Bio-CARe Women Scientists award by Department of Biotechnology (DBT), Government of India. YB was founded by the Conseil Régional des Pays de la Loire (MAGGIC project). We thank Dr Jitendra Vashist from Department of Biotechnology and Bioinformatics, Jaypee University of Information Technology, Waknaghat for providing his valuable support in conducting the 2D PAGE experiments.

\section{Conflict of Interest}


The authors have no substantial financial or commercial conflicts of interest with the current work or its publication.

\section{Ethical approval}

This article does not involve any study with human participants or animals to be performed by any of the authors. 


\section{Reference}

[1] GLOBAL TUBERCULOSIS REPORT 2018, 2018. http://apps.who.int/bookorders. (accessed May 21, 2019).

[2] J.L. Dahl, C.N. Kraus, H.I.M. Boshoff, B. Doan, K. Foley, D. Avarbock, G. Kaplan, V. Mizrahi, H. Rubin, C.E. Barry, The role of RelMtb-mediated adaptation to stationary phase in long-term persistence of Mycobacterium tuberculosis in mice., Proc. Natl. Acad. Sci. U. S. A. 100 (2003) 10026-31. doi:10.1073/pnas.1631248100.

[3] R. Singh, C.E. Barry, H.I.M. Boshoff, The Three RelE Homologs of Mycobacterium tuberculosis Have Individual, Drug-Specific Effects on Bacterial Antibiotic Tolerance, J. Bacteriol. 192 (2010) 1279-1291. doi:10.1128/JB.01285-09.

[4] K.N. Adams, K. Takaki, L.E. Connolly, H. Wiedenhoft, K. Winglee, O. Humbert, P.H. Edelstein, C.L. Cosma, L. Ramakrishnan, Drug Tolerance in Replicating Mycobacteria Mediated by a Macrophage-Induced Efflux Mechanism, Cell. 145 (2011) 39-53. doi:10.1016/j.cell.2011.02.022.

[5] R.K. Dhiman, S. Mahapatra, R.A. Slayden, M.E. Boyne, A. Lenaerts, J.C. Hinshaw, S.K. Angala, D. Chatterjee, K. Biswas, P. Narayanasamy, M. Kurosu, D.C. Crick, Menaquinone synthesis is critical for maintaining mycobacterial viability during exponential growth and recovery from non-replicating persistence, Mol. Microbiol. 72 (2009) 85-97. doi:10.1111/j.1365-2958.2009.06625.x.

[6] H.L. Kornberg, The role and control of the glyoxylate cycle in Escherichia coli., Biochem. J. 99 (1966) 1-11. http://www.ncbi.nlm.nih.gov/pubmed/5337756 (accessed March 28, 2019).

[7] M.C. Lorenz, G.R. Fink, Life and death in a macrophage: role of the glyoxylate cycle in virulence., Eukaryot. Cell. 1 (2002) 657-62. doi:10.1128/EC.1.5.657-662.2002. 
[8] M.F. Dunn, J.A. Ramírez-Trujillo, I. Herná Ndez-Lucas, Major roles of isocitrate lyase and malate synthase in bacterial and fungal pathogenesis, (n.d.). doi:10.1099/mic.0.030858-0.

[9] S. Sturgill-Koszycki, P.L. Haddix, D.G. Russell, The interaction betweenMycobacterium and the macrophage analyzed by two-dimensional polyacrylamide gel electrophoresis, Electrophoresis. 18 (1997) 2558-2565. doi:10.1002/elps.1150181411.

[10] J.E. Graham, J.E. Clark-Curtiss, Identification of Mycobacterium tuberculosis RNAs synthesized in response to phagocytosis by human macrophages by selective capture of transcribed sequences (SCOTS)., Proc. Natl. Acad. Sci. U. S. A. 96 (1999) 115549. http://www.ncbi.nlm.nih.gov/pubmed/10500215 (accessed March 28, 2019).

[11] H. Eoh, K.Y. Rhee, Multifunctional essentiality of succinate metabolism in adaptation to hypoxia in Mycobacterium tuberculosis, Proc. Natl. Acad. Sci. 110 (2013) 65546559. doi:10.1073/pnas.1219375110.

[12] M. Nandakumar, C. Nathan, K.Y. Rhee, ARTICLE Isocitrate lyase mediates broad antibiotic tolerance in Mycobacterium tuberculosis, (2014). doi:10.1038/ncomms5306.

[13] M. Gengenbacher, S.P.S. Rao, K. Pethe, T. Dick, Nutrient-starved, non-replicating Mycobacterium tuberculosis requires respiration, ATP synthase and isocitrate lyase for maintenance of ATP homeostasis and viability, Microbiology. 156 (2010) 81-87. doi:10.1099/mic.0.033084-0.

[14] T.A. Gould, H. van de Langemheen, E.J. Munoz-Elias, J.D. McKinney, J.C. Sacchettini, Dual role of isocitrate lyase 1 in the glyoxylate and methylcitrate cycles in Mycobacterium tuberculosis, Mol. Microbiol. 61 (2006) 940-947. doi:10.1111/j.13652958.2006.05297.x. 
[15] H. Eoh, K.Y. Rhee, Methylcitrate cycle defines the bactericidal essentiality of isocitrate lyase for survival of Mycobacterium tuberculosis on fatty acids., Proc. Natl. Acad. Sci. U. S. A. 111 (2014) 4976-81. doi:10.1073/pnas.1400390111.

[16] E.J. Munoz-Elias, A.M. Upton, J. Cherian, J.D. McKinney, Role of the methylcitrate cycle in Mycobacterium tuberculosis metabolism, intracellular growth, and virulence, Mol. Microbiol. 60 (2006) 1109-1122. doi:10.1111/j.1365-2958.2006.05155.x.

[17] S.T. Cole, R. Brosch, J. Parkhill, T. Garnier, C. Churcher, D. Harris, S. V. Gordon, K. Eiglmeier, S. Gas, C.E. Barry, F. Tekaia, K. Badcock, D. Basham, D. Brown, T. Chillingworth, R. Connor, R. Davies, K. Devlin, T. Feltwell, S. Gentles, N. Hamlin, S. Holroyd, T. Hornsby, K. Jagels, A. Krogh, J. McLean, S. Moule, L. Murphy, K. Oliver, J. Osborne, M.A. Quail, M.-A. Rajandream, J. Rogers, S. Rutter, K. Seeger, J. Skelton, R. Squares, S. Squares, J.E. Sulston, K. Taylor, S. Whitehead, B.G. Barrell, Deciphering the biology of Mycobacterium tuberculosis from the complete genome sequence, Nature. 393 (1998) 537-544. doi:10.1038/31159.

[18] E.J. Muñoz-Elías, J.D. McKinney, Mycobacterium tuberculosis isocitrate lyases 1 and 2 are jointly required for in vivo growth and virulence, Nat. Med. 11 (2005) 638-644. doi:10.1038/nm1252.

[19] V. Sharma, S. Sharma, K. Hoener zu Bentrup, J.D. McKinney, D.G. Russell, W.R. Jacobs, J.C. Sacchettini, Structure of isocitrate lyase, a persistence factor of Mycobacterium tuberculosis., Nat. Struct. Biol. 7 (2000) 663-8. doi:10.1038/77964.

[20] Y. Park, Y. Cho, Y.-H. Lee, Y.-W. Lee, S. Rhee, Crystal structure and functional analysis of isocitrate lyases from Magnaporthe oryzae and Fusarium graminearum, J. Struct. Biol. 194 (2016) 395-403. doi:10.1016/J.JSB.2016.03.019.

[21] Y.-V. Lee, S.B. Choi, H.A. Wahab, Y.S. Choong, Active Site Flexibility of 
Mycobacterium tuberculosis Isocitrate Lyase in Dimer Form, J. Chem. Inf. Model. 57 (2017) 2351-2357. doi:10.1021/acs.jcim.7b00265.

[22] T. V Pham, A.S. Murkin, M.M. Moynihan, L. Harris, P.C. Tyler, N. Shetty, J.C. Sacchettini, H.-L. Huang, T.D. Meek, Mechanism-based inactivator of isocitrate lyases 1 and 2 from Mycobacterium tuberculosis., Proc. Natl. Acad. Sci. U. S. A. 114 (2017) 7617-7622. doi:10.1073/pnas.1706134114.

[23] E.J. Muñoz-Elías, A.M. Upton, J. Cherian, J.D. McKinney, Role of the methylcitrate cycle in Mycobacterium tuberculosis metabolism, intracellular growth, and virulence, Mol. Microbiol. 60 (2006) 1109-1122. doi:10.1111/j.1365-2958.2006.05155.x.

[24] G.W. Plaut, R.L. Beach, T. Aogaichi, Alpha-methylisocitrate. A selective inhibitor of TPN-linked isocitrate dehydrogenase from bovine heart and rat liver., J. Biol. Chem. 250 (1975) 6351-4. http://www.ncbi.nlm.nih.gov/pubmed/239945 (accessed August 12, 2019).

[25] M. Brock, D. Darley, S. Textor, W. Buckel, 2-Methylisocitrate lyases from the bacterium Escherichia coli and the filamentous fungus Aspergillus nidulans, Eur. J. Biochem. 268 (2001) 3577-3586. doi:10.1046/j.1432-1327.2001.02262.x.

[26] S. Kumar, G. Stecher, M. Li, C. Knyaz, K. Tamura, MEGA X: Molecular Evolutionary Genetics Analysis across Computing Platforms., Mol. Biol. Evol. 35 (2018) 1547-1549. doi:10.1093/MOLBEV/MSY096.

[27] X. Robert, P. Gouet, Deciphering key features in protein structures with the new ENDscript server, Nucleic Acids Res. 42 (2014) W320-W324. doi:10.1093/nar/gku316.

[28] J. Yang, R. Yan, A. Roy, D. Xu, J. Poisson, Y. Zhang, The I-TASSER Suite: protein 
structure and function prediction, Nat. Methods. 12 (2015) 7-8.

doi:10.1038/nmeth.3213.

[29] Molecular Cloning This is a free sample of content from Molecular Cloning: A Laboratory Manual, 4th edition. Click here for more information or to buy the book, 2012. www.cshlpress.org.

[30] V.N. Popov, E.A. Moskalev, M.U. Shevchenko, A.T. Eprintsev, Comparative Analysis of Glyoxylate Cycle Key Enzyme Isocitrate Lyase from Organisms of Different Systematic Groups, J. Evol. Biochem. Physiol. 41 (2005) 631-639. doi:10.1007/s10893-006-0004-3.

[31] K. Britton, S. Langridge, P.J. Baker, K. Weeradechapon, S.E. Sedelnikova, J.R. De Lucas, D.W. Rice, G. Turner, The crystal structure and active site location of isocitrate lyase from the fungus Aspergillus nidulans., Structure. 8 (2000) 349-62. http://www.ncbi.nlm.nih.gov/pubmed/10801489 (accessed March 28, 2019).

[32] S.J. Joseph, P. Hugenholtz, P. Sangwan, C.A. Osborne, P.H. Janssen, Laboratory cultivation of widespread and previously uncultured soil bacteria., Appl. Environ. Microbiol. 69 (2003) 7210-5. doi:10.1128/aem.69.12.7210-7215.2003.

[33] P.H. Janssen, P.S. Yates, B.E. Grinton, P.M. Taylor, M. Sait, Improved culturability of soil bacteria and isolation in pure culture of novel members of the divisions Acidobacteria, Actinobacteria, Proteobacteria, and Verrucomicrobia., Appl. Environ. Microbiol. 68 (2002) 2391-6. doi:10.1128/aem.68.5.2391-2396.2002.

[34] M. Theses, M.N. Fawaz, Trace: Tennessee Research and Creative Exchange Revealing the Ecological Role of Gemmatimonadetes Through Cultivation and Molecular Analysis of Agricultural Soils, n.d. https://race.tennessee.edu/utk_gradthes/1652 (accessed May 27, 2019). 
[35] J. V. Schloss, W.W. Cleland, Inhibition of isocitrate lyase by 3-nitropropionate, a reaction-intermediate analog, Biochemistry. 21 (1982) 4420-4427. doi:10.1021/bi00261a035.

[36] K. Höner Zu Bentrup, A. Miczak, D.L. Swenson, D.G. Russell, Characterization of activity and expression of isocitrate lyase in Mycobacterium avium and Mycobacterium tuberculosis., J. Bacteriol. 181 (1999) 7161-7. http://www.ncbi.nlm.nih.gov/pubmed/10572116 (accessed March 28, 2019).

[37] W. Zhai, F. Wu, Y. Zhang, Y. Fu, Z. Liu, The Immune Escape Mechanisms of Mycobacterium Tuberculosis, Int. J. Mol. Sci. 20 (2019) 340. doi:10.3390/ijms20020340.

[38] H. Zhang, Y. Sekiguchi, S. Hanada, P. Hugenholtz, H. Kim, Y. Kamagata, K. Nakamura, Gemmatimonas aurantiaca gen. nov., sp. nov., a Gram-negative, aerobic, polyphosphate-accumulating micro-organism, the first cultured representative of the new bacterial phylum Gemmatimonadetes phyl. nov., Int. J. Syst. Evol. Microbiol. 53 (2003) 1155-1163. doi:10.1099/ijs.0.02520-0.

[39] S. Spring, B. Bunk, C. Spröer, P. Schumann, M. Rohde, B.J. Tindall, H.-P. Klenk, Characterization of the first cultured representative of Verrucomicrobia subdivision 5 indicates the proposal of a novel phylum, ISME J. 10 (2016) 2801-2816. doi:10.1038/ismej.2016.84.

[40] N.L. Ward, J.F. Challacombe, P.H. Janssen, B. Henrissat, P.M. Coutinho, M. Wu, G. Xie, D.H. Haft, M. Sait, J. Badger, R.D. Barabote, B. Bradley, T.S. Brettin, L.M. Brinkac, D. Bruce, T. Creasy, S.C. Daugherty, T.M. Davidsen, R.T. DeBoy, J.C. Detter, R.J. Dodson, A.S. Durkin, A. Ganapathy, M. Gwinn-Giglio, C.S. Han, H. Khouri, H. Kiss, S.P. Kothari, R. Madupu, K.E. Nelson, W.C. Nelson, I. Paulsen, K. 
Penn, Q. Ren, M.J. Rosovitz, J.D. Selengut, S. Shrivastava, S.A. Sullivan, R. Tapia, L.S. Thompson, K.L. Watkins, Q. Yang, C. Yu, N. Zafar, L. Zhou, C.R. Kuske, Three genomes from the phylum Acidobacteria provide insight into the lifestyles of these microorganisms in soils., Appl. Environ. Microbiol. 75 (2009) 2046-2056. doi:10.1128/AEM.02294-08.

[41] F. Schmitzberger, A.G. Smith, C. Abell, T.L. Blundell, Comparative analysis of the Escherichia coli ketopantoate hydroxymethyltransferase crystal structure confirms that it is a member of the (betaalpha) 8 phosphoenolpyruvate/pyruvate superfamily., J. Bacteriol. 185 (2003) 4163-71. doi:10.1128/jb.185.14.4163-4171.2003.

[42] J. Campos-Garcia, C. Diaz-Perez, A.L. Diaz-Perez, Residues Asn214, Gln211, Glu219 and Gln 221 contained in the subfamily 3 catalytic signature of the isocitrate lyase from Pseudomonas aeruginosa are involved in its catalytic and thermal properties, World J. Microbiol. Biotechnol. 29 (2013) 991-999. doi:10.1007/s11274-013-1258-8.

[43] S. Watanabe3, Y. Takada, Amino acid residues involved in cold adaptation of isocitrate lyase from a psychrophilic bacterium, Colwellia maris, (n.d.). doi:10.1099/mic.0.27201-0.

[44] F. Gabriel, I. Accoceberry, J.-J. Bessoule, B. Salin, M. Lucas-Guérin, S. Manon, K. Dementhon, T. Noël, A Fox2-dependent fatty acid ß-oxidation pathway coexists both in peroxisomes and mitochondria of the ascomycete yeast Candida lusitaniae., PLoS One. 9 (2014) e114531. doi:10.1371/journal.pone.0114531.

[45] S. Cortassa, S.J. Sollott, M.A. Aon, Mitochondrial respiration and ROS emission during \$ $\beta$-oxidation in the heart: An experimental-computational study., PLoS Comput. Biol. 13 (2017) e1005588. doi:10.1371/journal.pcbi.1005588.

[46] M.M. Chan, N. Adapala, C. Chen, Peroxisome Proliferator-Activated Receptor- $\gamma$ - 
Mediated Polarization of Macrophages in Leishmania Infection, PPAR Res. 2012 (2012) 1-11. doi:10.1155/2012/796235.

[47] A. Anand, P. Verma, A.K. Singh, S. Kaushik, R. Pandey, C. Shi, H. Kaur, M. Chawla, C.K. Elechalawar, D. Kumar, Y. Yang, N.S. Bhavesh, R. Banerjee, D. Dash, A. Singh, V.T. Natarajan, A.K. Ojha, C.C. Aldrich, R.S. Gokhale, Polyketide Quinones Are Alternate Intermediate Electron Carriers during Mycobacterial Respiration in OxygenDeficient Niches, Mol. Cell. 60 (2015) 637-650. doi:10.1016/j.molcel.2015.10.016.

[48] B.M. Cumming, M.A. Rahman, D.A. Lamprecht, K.H. Rohde, V. Saini, J.H. Adamson, D.G. Russell, A.J.C. Steyn, Mycobacterium tuberculosis arrests host cycle at the G1/S transition to establish long term infection, PLOS Pathog. 13 (2017) e1006389. doi:10.1371/journal.ppat.1006389.

[49] A. Crits-Christoph, S. Diamond, C.N. Butterfield, B.C. Thomas, J.F. Banfield, Novel soil bacteria possess diverse genes for secondary metabolite biosynthesis, Nature. 558 (2018) 440-444. doi:10.1038/s41586-018-0207-y.

\section{Figure Legends}

\section{Figure 1}

Phylogenetic tree representing the evolutionary relationship between different ICLs. Rv1916 is found to be more related to soil bacteria. Mtb ICLs are represented in box and the soil bacteria are highlighted in brackets

\section{Figure 2}

(A) Schematic representation of M. tuberculosis H37Rv ICLs and eukaryotic A. nidulans ICL. Domain I includes the conserved catalytic motif "KKCGH" which is present in Rv1915 but absent in Rv1916. Domain II of $\sim 100$ consecutive amino acids A. nidulans (267-363) is unique to eukaryotic ICLs and absent in Rv0467. The grey box (QSEGE) in Rv1916 appears 
to be equivalent to the consensus signature $\mathrm{QIENQ}_{\mathrm{I}} \mathrm{V}_{\mathrm{SDE}} \mathrm{EQCGHQD}_{\mathrm{C}}$ for ICL of the catalytic loop in P. aeruginosa [42]. Other invariant residues involved in ICL activity are also marked. Domain IV present in Rv1916 is exclusive to mycobacterial ICL2/AceA. (B) Seconadary structure prediction of Rv1916 using templates 1DQU and 1TUW. 1DQU align with 1-235 residues of Rv1916 whereas 1TUW partially align with 253-386 residues. Active site residues of 1DQU invovled in ICL and MICL activity are marked by asterisk (*) and black circle $(\bullet)$ respectively. T154 of RV1916 is a common residues for ICL and MICL activity (marked by $\bullet$ ). Active site residues of 1TUW are marked by triangle $(\boldsymbol{\nabla})$.

\section{Figure 3}

(A) Expression and localization of Rv1916: Lane 1- Medium range protein marker; Lane 2: Total cell lysate of uninduced sample; Lane 3: Total cell lysate of induced sample; Lane 4: Insoluble fraction; Lane 5: Soluble Fraction (B) SDS PAGE analysis of purification procedure of Rv1916: Lane 1- Medium range protein marker; Lane 2: Insoluble fraction; Lane 3: Soluble Fraction; Lane 4: Flow through; Lane 5: Wash; Lane: 6 and 7: Eluted fractions with $2.5 \mathrm{mM}$ Desthiobiotin. (C) Gel Filtartion Chromatography of Rv1916 on Superdex 200 column: The calibration curve with known molecular standards i.e. Thyroglobulin $(670 \mathrm{kDa})$, Ferritin $(440 \mathrm{kDa})$, Aldolase $(158 \mathrm{kDa})$ and Ovalbumin $(44 \mathrm{kDa})$ is shown in the inset of the GFC profile; (D) 2D-PAGE of Rv1916: Coomassie blue stained SDS-PAGE gel of Rv1916 with broader range protein marker. $\mathrm{pH}$ gradations of the linear IPG strip (pH 3-10) are displayed on the top of the gel.

\section{Figure 4}

Lineweaver-Burk plots to determine the kinetic parameters of Mtb ICLs. The plots for ICL activity of ICL2b and ICL1 (A \& C respectively), indicates 4-fold higher $\mathrm{K}_{\mathrm{m}}$ for the former (13 $\mu \mathrm{M}$ as opposed $3.25 \mu \mathrm{M})$, whereas the difference in the $\mathrm{K}_{\mathrm{m}}(300 \mu \mathrm{M}$ as opposed $241 \mu \mathrm{M})$ is not so obvoius for MICL activities of the two enzymes (B \& D). The representative time 
dependent activity profile with $50 \mu \mathrm{M}$ isocitrate and $500 \mu \mathrm{M}$ methylisocitrate, in absence () or in presence (-๑-) of $2 \mu \mathrm{M}$ 3-NP for Rv1916 (10 and $25 \mu \mathrm{gs}$ for ICL and MICL activities respectively) and Rv0467 ( 2 and $5 \mu$ gs for ICL and MICL activities respectively) is depicted in inset of each figure. The inhibition constant $\mathrm{K}_{\mathrm{i}}$ of 3-NP for Rv1916 is $7.9 \mu \mathrm{M}$ and 135.5 $\mu \mathrm{M}$ and $\mathrm{Rv} 0467$ is $7.4 \mu \mathrm{M}$ and $240.4 \mu \mathrm{M}$ for ICL and MICL respectively. 


\section{Supporting Information}

\section{International Journal of Biological Macromolecules}

\section{Structure Function insights into elusive Mycobacterium tuberculosis protein Rv1916}

Monika Antil $^{\mathrm{a}}$, Jyoti Sharma ${ }^{\mathrm{b}, \mathrm{c}}$, Yoan Brissonnet ${ }^{\mathrm{d}}$, Monika Choudhary ${ }^{\mathrm{e}}$, Sébastien Gouin $^{\text {, }}$, and Vibha Gupta*

a Department of Biotechnology, Jaypee Institute of Information Technology, Noida - 201309, India

${ }^{\mathrm{b}}$ Institute of Bioinformatics, International Technology Park, Bangalore, 560066 India

${ }^{c}$ Manipal Academy of Higher Education (MAHE), Manipal 576104, Karnataka, India

${ }^{\mathrm{d} C E I S A M}$, Chimie Et Interdisciplinarité, Synthèse, Analyse, Modélisation, UMR CNRS 6230, UFR des Sciences et des Techniques, Université de Nantes, 2 rue de la Houssinière, BP 92208, 44322, Nantes Cedex 3, France.

e Department of Biotechnology and Bioinformatics, Jaypee University of Information Technology, Waknaghat - 173234, India

*Corresponding author: Dr. Vibha Gupta

Department of Biotechnology

Jaypee Institute of Information Technology

A-10, Sector-62, Noida- 201309

Uttar Pradesh, India

Email: vibha.gupta@jiit.ac.in

Co-authors:

Monika Antil

Email: monikaantil60@gmail.com

Jyoti Sharma

Email: jyotibioinfo@gmail.com

Yoan Brissonnet

Email: yoan.brissonnet@univ-nantes.fr

Sébastien Gouin

Email: Sebastien.Gouin@univ-nantes.fr

Monika Choudhary

Email: monikachoudhary485@gmail.com 

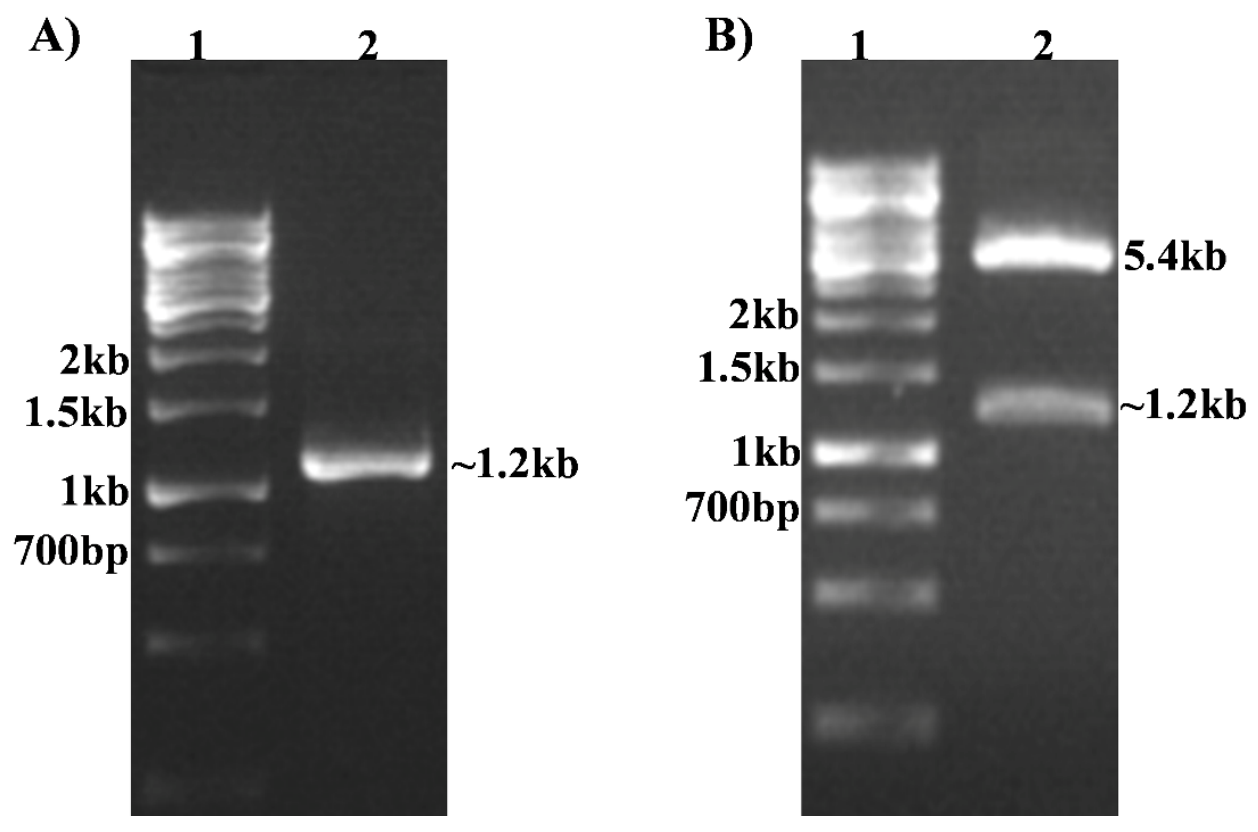

Fig. S1: Cloning of gene encoding Rv1916 in pET21c vector (A) PCR amplification of rv1916 gene. $1 \mathrm{~kb}$ DNA ladder in lane 1 is used to estimate the $1.2 \mathrm{~kb}$ size of PCR amplicon in lane 2 (B) Confirmation of positive recombinant clone by restriction digestion with NheI and HindIII. Lane 1- 1 $\mathrm{kb}$ DNA Ladder, Lane 2: Digested pattern corresponding to $5.4 \mathrm{~kb}$ band of vector and fall out of inserted gene of $1.2 \mathrm{~kb}$ size. 
Table S1: Pairwise sequence alignment of Rv1916 with representative ICL superfamily members in the PDB database

\begin{tabular}{|l|l|l|c|c|c|c|}
\hline \multicolumn{1}{|c|}{ Family } & $\begin{array}{c}\text { PDB ID } \\
\text { (Resolution) }\end{array}$ & \multicolumn{1}{|c|}{ Organism } & $\begin{array}{c}\text { Sequence } \\
\text { length }\end{array}$ & $\begin{array}{c}\text { \% } \\
\text { Identity }\end{array}$ & $\begin{array}{c}\text { \% } \\
\text { Similarity }\end{array}$ & $\begin{array}{c}\text { \% Query } \\
\text { coverage }\end{array}$ \\
\hline $\begin{array}{l}\text { Eukaryotic } \\
\text { ICL }\end{array}$ & 1DQU $(2.8 \AA)$ & A. nidulans & 538 & 40 & 57 & 69 \\
\hline $\begin{array}{l}\text { Prokaryotic } \\
\text { ICL }\end{array}$ & 1F6I $(2.25 \AA)$ & M. tuberculosis & 428 & 48 & 62 & 59 \\
\hline MICL & 1OQF $(1.93 \AA)$ & E. coli & 296 & 25 & 38 & 34 \\
\hline DMML & 3FA4 $(2.6 \AA)$ & A. niger & 302 & 33 & 47 & 22 \\
\hline OAH & 3LYE $(1.3 \AA)$ & E. coli & 307 & 47 & 58 & 4 \\
\hline OAD & 3B8I $(1.9 \AA)$ & P. aeruginosa & 287 & 25 & 37 & 23 \\
\hline PDP & 1ZLP $(2.7 \AA)$ & D. caryophyllus & 318 & 67 & 77 & 3 \\
\hline DFA0005 & 2ZE3 $(1.65 \AA)$ & D. ficus & 275 & 30 & 55 & 11 \\
\hline KPHMT & 1M3U $(1.8 \AA)$ & E. coli & 264 & 33 & 52 & 8 \\
\hline MLL9387 & 2P10 $(2.15 \AA)$ & R. loti & 286 & 33 & 53 & 25 \\
\hline
\end{tabular}


Table S2: BlastP Search of Rv1916 with NCBI non-redundant database after excluding the protein sequences from Mycobacteriaceae family

\begin{tabular}{|l|c|c|c|c|l|}
\hline \multicolumn{1}{|c|}{ Organisms } & $\begin{array}{l}\text { Sequence } \\
\text { Length }\end{array}$ & $\begin{array}{c}\text { Query } \\
\text { coverage }\end{array}$ & $\begin{array}{c}\text { \% } \\
\text { Identity }\end{array}$ & $\begin{array}{c}\text { \% } \\
\text { Similarity }\end{array}$ & \multicolumn{1}{c|}{ Domain } \\
\hline $\begin{array}{l}\text { Isocitrate Lyase, } \\
\text { partial } \\
\text { Gemmatimonadetes } \\
\text { bacterium }\end{array}$ & 677 & 99 & 79 & 87 & $\begin{array}{l}\text { Members of ICL/PEPM_KPHMT } \\
\text { enzyme superfamily catalyse the } \\
\text { formation and cleavage of either P- } \\
\text { C or C-C bonds }\end{array}$ \\
\hline $\begin{array}{l}\text { Isocitrate Lyase } \\
\text { Verrucomicrobia } \\
\text { bacterium }\end{array}$ & 782 & 95 & 78 & 90 & $\begin{array}{l}\text { Members of ICL/PEPM_KPHMT } \\
\text { enzyme superfamily catalyse the } \\
\text { formation and cleavage of either P- } \\
\text { C or C-C bonds }\end{array}$ \\
\hline $\begin{array}{l}\text { Isocitrate Lyase, } \\
\text { partial } \\
\text { Verrucomicrobia } \\
\text { bacterium }\end{array}$ & 345 & 86 & 79 & 90 & $\begin{array}{l}\text { Members of ICL/PEPM_KPHMT } \\
\text { enzyme superfamily catalyse the } \\
\text { formation and cleavage of either P- } \\
\text { C or C-C bonds }\end{array}$ \\
\hline $\begin{array}{l}\text { Isocitrate lyase } \\
\text { family protein } \\
\begin{array}{l}\text { Acidobacteria } \\
\text { bacterium }\end{array}\end{array}$ & 755 & 99 & 71 & 83 & $\begin{array}{l}\text { Members of ICL/PEPM_KPHMT } \\
\text { enzyme superfamily catalyse the } \\
\text { formation and cleavage of either P- } \\
\text { C or C-C bonds }\end{array}$ \\
\hline
\end{tabular}


Table S3A: Gene cluster of Rv1916

\begin{tabular}{|c|l|}
\hline Gene & \multicolumn{1}{|c|}{ Function } \\
\hline Rv1914 & $\begin{array}{l}\text { Unknown protein. Predicted to } \\
\text { be an outer membrane protein }\end{array}$ \\
\hline Rv1915 & Isocitrate lyase AceAa \\
\hline Rv1916 & Isocitrate lyase AceAb \\
\hline Rv1917 & PPE family protein PPE34 \\
\hline $\mathbf{R v 1 9 1 8}$ & PPE family protein PPE35 \\
\hline $\mathbf{R v 1 9 1 9}$ & Polyketide_cyc2 \\
\hline $\mathbf{R v 1 9 2 0}$ & Acyltransferase \\
\hline $\mathbf{R v 1 9 2 1}$ & Lipoprotein LppF, Hydrolase \\
\hline
\end{tabular}

Table S3B: Gene cluster of Tetracenomycin F2 Cyclase

\begin{tabular}{|c|l|}
\hline Gene & \multicolumn{1}{c|}{ Function } \\
\hline SGLAU_26325 & Tetracenomycin C resistance and Export Protein \\
\hline SGLAU_26330 & Tetracenomycin polyketide synthesis O-methyltransferase TcmP \\
\hline SGLAU_26335 & Tetracenomycin polyketide synthesis hydroxylase TcmG \\
\hline SGLAU_26340 & Tetracenomycin polyketide synthesis hydroxylase TcmH \\
\hline SGLAU_26345 & Tetracenomycin F2 cyclase TcmI \\
\hline SGLAU_26350 & $\begin{array}{l}\text { Tetracenomycin polyketide synthesis protein TcmJ, putative B-ring } \\
\text { cyclase }\end{array}$ \\
\hline SGLAU_26355 & Tetracenomycin C polyketide putative beta-ketoacyl synthase 1 \\
\hline SGLAU_26360 & Tetracenomycin C polyketide putative beta-ketoacyl synthase 2 \\
\hline SGLAU_26365 & Minimal PKS acyl carrier protein TcmM \\
\hline SGLAU_26370 & Multifunctional cyclase-dehydratase-3-O-methyl transferase TcmN \\
\hline SGLAU_26375 & Tetracenomycin polyketide synthesis 8-O-methyl transferase TcmO \\
\hline
\end{tabular}




\section{Modelling of Rv1916}

\section{Methodology:}

The three-dimensional structure of Rv1916 was generated using I-TASSER server (https://zhanglab.ccmb.med.umich.edu/I-TASSER/). I-TASSER is a modelling sever which employ profile-profile threading alignment (PPA) for recognition of the protein fold from PDB and congregating the fragments of the PDB templates for the generation of threedimensional structure of the given target protein [28]. Accuracy of the generated models was estimated by confidence score, predicted TM-score and RMSD. It also allows the annotation of possible function of the target protein through ligand binding site, enzyme commission numbers and active sites and gene ontology terms.

\section{Results:}

I-TASEER generate five full-length models of Rv1916 using 1DQU as a template and also calculate the scores of all the parameters for the validation of the generated models (Table S4). Fig. S2 shows the alignment of 1DQU and the best model structure of Rv1916. 1DQU is the best template selected for the building of Rv1916 structure with $0.54 \%$ query coverage and $0.35 \%$ identity. The $\mathrm{C}$-score of the predicted model is -3.09 which lies within the range of -5 to 2. Although scoring of the validation factors including C-score, is quite low they all lies within range calculated by I-TASSER. Also, the predicted EC number (4.1.3.1) and GO terms (GO: 0016833 for molecular function) of model annotate Rv1916 as isocitrate lyase particularly oxo-acid-lyase.

Table S4: Parameters for the validation of the model

\begin{tabular}{|l|c|c|c|c|c|c|c|}
\hline Parameters & $\begin{array}{c}\text { PDB } \\
\text { Hit }\end{array}$ & $\begin{array}{c}\text { Query } \\
\text { Coverage } \\
\mathbf{( \% )}\end{array}$ & $\begin{array}{c}\text { Identity } \\
\mathbf{( \% )}\end{array}$ & $\begin{array}{c}\text { Normalized } \\
\text { Z-score } \\
\text { [Range] }\end{array}$ & $\begin{array}{c}\text { C-score } \\
\text { [Range] }\end{array}$ & $\begin{array}{c}\text { TM- } \\
\text { score } \\
\text { [Range] }\end{array}$ & $\begin{array}{c}\text { RMS } \\
\text { D }\end{array}$ \\
\hline${ }^{\text {aModel }}$ & 1DQU_A & 0.54 & 0.35 & 1.16 & -3.09 & $0.37 \pm 0.12$ & $14.4 \pm$ \\
{$[>0.5]$} & $3.7 \AA$ \\
\hline $\begin{array}{l}\text { Ligand } \\
\text { Binding Site }\end{array}$ & 5E9G_B & - & - & - & 0.21 & - & - \\
\hline $\begin{array}{l}{ }^{b} \text { Enzyme } \\
\text { Commission } \\
\text { numbers and } \\
\text { active sites }\end{array}$ & 1DQU_A & 0.535 & 0.352 & - & 0.094 & 0.530 & 0.76 \\
\hline $\begin{array}{l}{ }^{\mathrm{b}} \text { Gene } \\
\text { Ontology } \\
\text { Terms }\end{array}$ & 1DQU_A & 0.54 & 0.35 & - & 0.09 & 0.5301 & 0.76 \\
\hline
\end{tabular}

Normalized Z-score is the normalized Z-score of the threading alignments. Alignment with a Normalized Z-score $>1$ mean a good alignment and vice versa.

${ }^{\mathrm{a}} \mathrm{C}$-score is a confidence score for estimating the quality of predicted models. It is calculated based on the significance of threading template alignments and the convergence parameters of the structure assembly simulations

${ }^{\mathrm{b}} \mathrm{C}$-score is a combined measure for evaluating global and local similarity between query and template protein 
TM-score is a recently proposed scale for measuring the structural similarity between two structures RMSD is an average distance of all residue pairs in two structures, a local error.

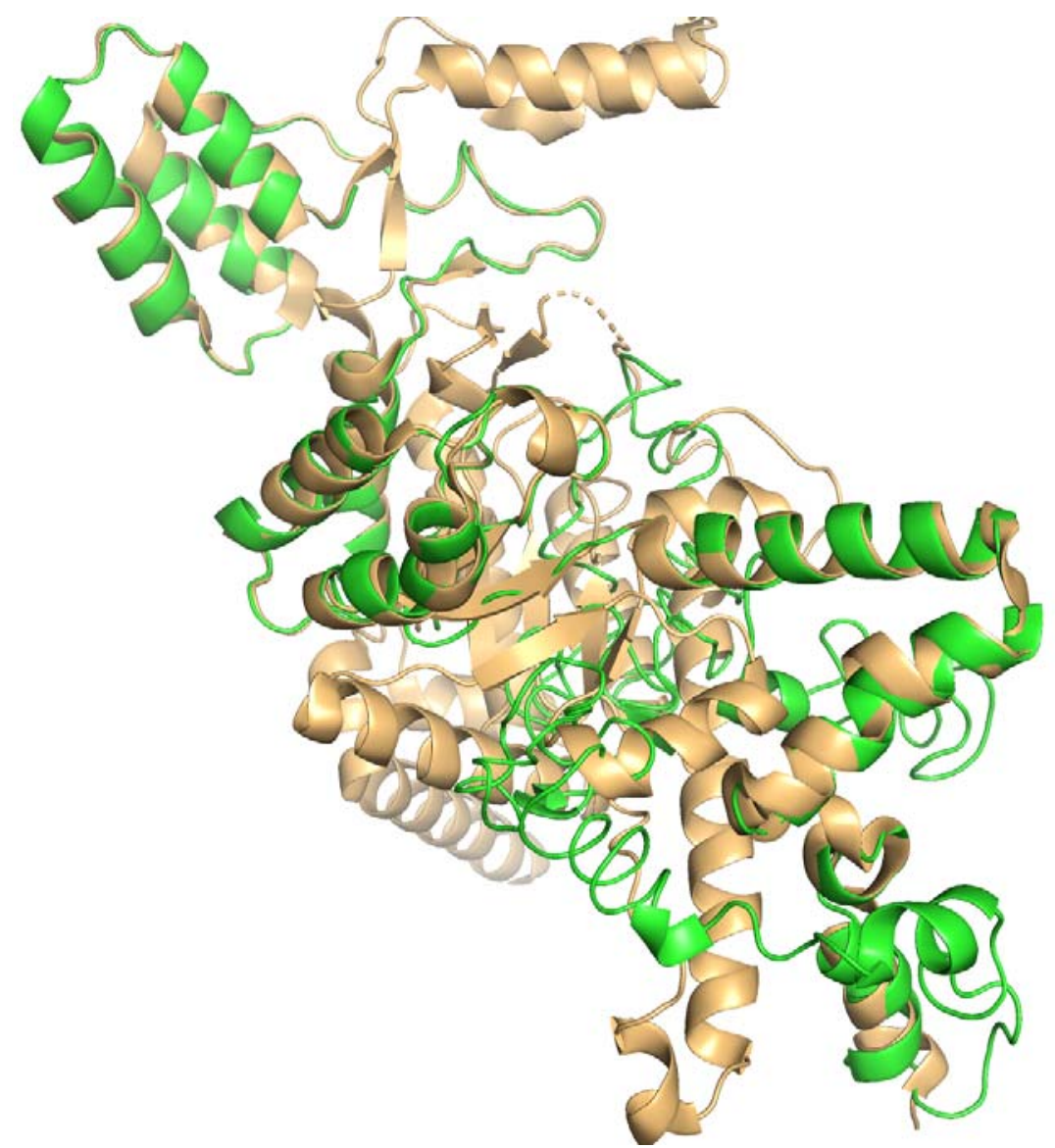

Fig. S2: Superimposition of Rv1916 structure model on to 1DQU structure. Green colour cartoon shows the model structure of Rv1916 whereas pale orange colour cartoon represents the structure of 1DQU. 